\title{
EVALUATION OF BROWN PLANTHOPPER Nilaparvata lugens (stal) RESISTANCE IN Oryza nivara WILD RICE ACCESSIONS FOUND IN SRI LANKA
}

\author{
S.A.P. Madurangi ${ }^{1}$, D. Ratnasekera ${ }^{1 *}$, P.V. Hemachandra ${ }^{2}$ and S.G.J.N. Senanayake ${ }^{1}$ \\ ${ }^{1}$ Faculty of Agriculture, University of Ruhuna, Sri Lanka \\ ${ }^{2}$ Rice research and Development Institute, Batalagoda, Sri Lanka \\ E-mail-disnar@agbio.ruh.ac.lk*, Tel- ++94718232808, Fax- ++94412292382/4
}

\begin{abstract}
Brown planthopper (BPH), Nilaparvata lugens Stal is one of the most serious rice pests in Sri Lanka. The study evaluated the nature of BPH resistance in seventeen $O$. nivara (WRAC 01, 02, 04, 07, 11, $12,14,19,21,22,24,25,35,41,46,62$, and 9864) accessions collected from different locations in Sri Lanka using standard seed box screening test. Ptb 33(resistant), Bg 379/2, Bg 300(moderately resistant) and $\mathrm{Bg} 380$ (susceptible) were used as check varieties. BPH culture maintained at the Rice Research and Development Institute, Batalagoda on Bg 380 was used for the test. BPH damage was scored (0-to9 scale) according to the standard evaluation system for rice, developed by International Rice Research Institute. According to the results WRAC 04, 41, 25 and Ptb 33 recorded as resistant (score 0-3), WRAC 46, 35, 24, 22, 21, 14, 7, 2,1, 9864 and Bg 379/2 as resistant to moderately resistant (score 3.14.0), WRAC 11, 12 and Bg 300 as moderately resistant (score 4.1-5.0), WRAC 19 and 62 as moderately resistant to moderately susceptible (score 5.1-6.0), while no checked accessions were recorded as susceptible to the BPH indicating potential of using Oryza nivara as a source of BPH resistance.
\end{abstract}

Keywords: Brown planthopper, Oryza nivara, Wild rice, Standard seed box screening test

\section{INTRODUCTION}

Brown Plant Hopper (BPH) Nilarpavata lugens (stal) (Homoptera: Delphacidae) is one of the most important insect pest in rice. BPH is the most destructive and widespread insect through out the rice growing areas in Asia. In Sri Lanka nearly 5-10\% of annual rice production is lost due to BPH damage (Nugaliyadda et al., 2001). At present, farmers mostly depend on chemical pesticides for the control of this pest (Kudagamage and Nugaliyadda, 1995). This dependence leads to many adverse effects. Host plant resistance is identified as the most effective way of BPH management. The varietal resistance is the most economic, least complicated and environmental friendly approach for the control of insect pest damages (Pathak and Kush, 1979). Rice is an annual grass that belongs to genus Oryza which includes 20 wild species. These wild relatives of rice constitute important genes for rice improvement; new sources of resistance to pests and diseases. Identification and characterizing of them may assist for future transfer of genes from wild rice to cultivated rice varieties. $O$. nivara is the most common and widely distributed wild rice species found in Sri Lanka (Hemachandra et $a l ., 2010)$. It contains AA genome like $O$. sativa. Hence identification of BPH resistance in $O$. nivara is very useful for the rice variety improvement programs in Sri Lanka. Bioassay using standard seed box screening test has been effectively used for screening resistant lines (Heinrichs et al., 1985). Therefore, present study planned to evaluate BPH resistance in selected $O$. nivara accessions using standard seed box screening test method.

\section{MATERIALS AND METHODS}

\subsection{PLANT MATERIALS}

Seventeen $O$. nivara accessions collected from different locations in Sri Lanka (Table 1) and maintained by the Rice Research and Development institute (RRDI), Bathalagoda and Ptb 33

Proceedings of the 15 ${ }^{\text {th }}$ International Forestry and Environment Symposium, 26-27 November 2010.

Published by Department of Forestry and Environmental Science, University of Sri Jayewardenepura, Sri Lanka. 
(resistant check), Bg 380 (susceptible check), Bg 379/2, Bg 300(moderately resistant check) varieties were used for the study.

Table 1: The accession numbers and collected locations of $O$. nivara

\begin{tabular}{lll}
\hline Accession No & Collected Location & District \\
\hline WRAC 01 & Bulunawewa & Matale \\
WRAC 02 & Pelbediyawa & Matale \\
WRAC 04 & Otththapahuwa & Anuradhapura \\
WRAC 07 & Ilakkttuwa & Puttlam \\
WRAC 11 & Kabaraya wewa, Poonewa & Anuradhapura \\
WRAC 12 & Sangilikulama wewa & Anuradhapura \\
WRAC 14 & Yakadapotha & Kurunegala \\
WRAC 19 & Ihalawewa & Anuradhapura \\
WRAC 21 & Inamaluwa & Matale \\
WRAC 22 & Rangirigama & Matale \\
WRAC 24 & A-9 road 105Km post & Anuradhapura \\
WRAC 25 & A-9 road 105Km post & Anuradhapura \\
WRAC 35 & Olugaskade tank & Anuradhapura \\
WRAC 41 & Paranagama & Matale \\
WRAC 46 & Mahiyanganaya & Badulla \\
WRAC 62 & Meegahawewa, Weerawewa & Anuradhapura \\
9864 & Matara & Matara \\
\hline
\end{tabular}

\subsection{BPH BIOASSY}

Experiment was conducted in the screen house at RRDI, Bathalagoda. BPH culture maintained at RRDI, Bathalagoda on susceptible rice variety, $\mathrm{Bg} 380$ was used for the test. Bioassay was done following the standard seed box screening test method. Seeds of tested $O$. nivara accessions and check varieties were sown in a galvanized tray $(60 * 40 * 10)$ filled with sterilized soil $5 \mathrm{~cm}$ deep. The seeds were sown in $40 \mathrm{~cm}$ long-rows and spaced $5 \mathrm{~cm}$ among rows. When the seedlings were 7 days old (at 3 leaf stage), they were infested with $2^{\text {nd }}$ instars nymphs at the rate of 3nymps/seedling. Complete Randomized design (CRD) with four replicates was applied for the test. The standard evaluation system for rice, developed by International Rice Research Institute (IRRI), in 1980 was used to score the BPH damage. BPH damage was rated by a 0 -to- 9 scale (Table 2 ).

Table 2: Standard evaluation system of BPH resistance in rice

\begin{tabular}{ll}
\hline Scale value & Type of resistance \\
\hline $\mathbf{0 . 0 - 3 . 0}$ & Resistant(R) \\
3.1-4.0 & Resistant/Moderately Resistant(R/MR) \\
4.1-5.0 & Moderately Resistant(MR) \\
$\mathbf{5 . 1 - 6 . 0}$ & Moderately Resistant/Moderately Susceptible(MR/MS) \\
6.1-7.0 & Moderately Susceptible(MS) \\
7.0< & Susceptible(S) \\
\hline
\end{tabular}

\section{RESULTS AND DISCUSSION}

BPH resistance has been identified in a wide range of traditional rice varieties and wild rice species (Pathak \& Khush 1979 and Heinrichs et al. 1985). Scientists have already characterized and exploited some resistant species and upgraded cultivated rice varieties. To 
date these varieties play a significant role in controlling BPH outbreaks in rice cultivations. However development of virulent BPH populations is becoming a serious threat for rice cultivation at present. Thus, constant search for resistant species is very important. Several reports have highlighted wild rice species of $O$. latifolia, $O$. nivara, $O$. punctata and $O$. minuta as important sources of BPH resistance (Wu et al. 1986).

Results of the standard seed box screening test showed that tested $O$. nivara accessions were almost resistant to the Sri Lankan BPH. Lowest mean damage scores were recoded in Ptb 33, WRAC 04, WRAC 25, WRAC 41, WRAC 01, WRAC 02, WRAC 07, WRAC 14, WRAC 21, WRAC 22, WRAC 24, WRAC 35, WRAC 46, 9864 and Bg 379/2 accessions and varieties indicating their resistant nature to the $\mathrm{BPH}$. Highest mean damage score was recorded in variety Bg 380(Fig.1).

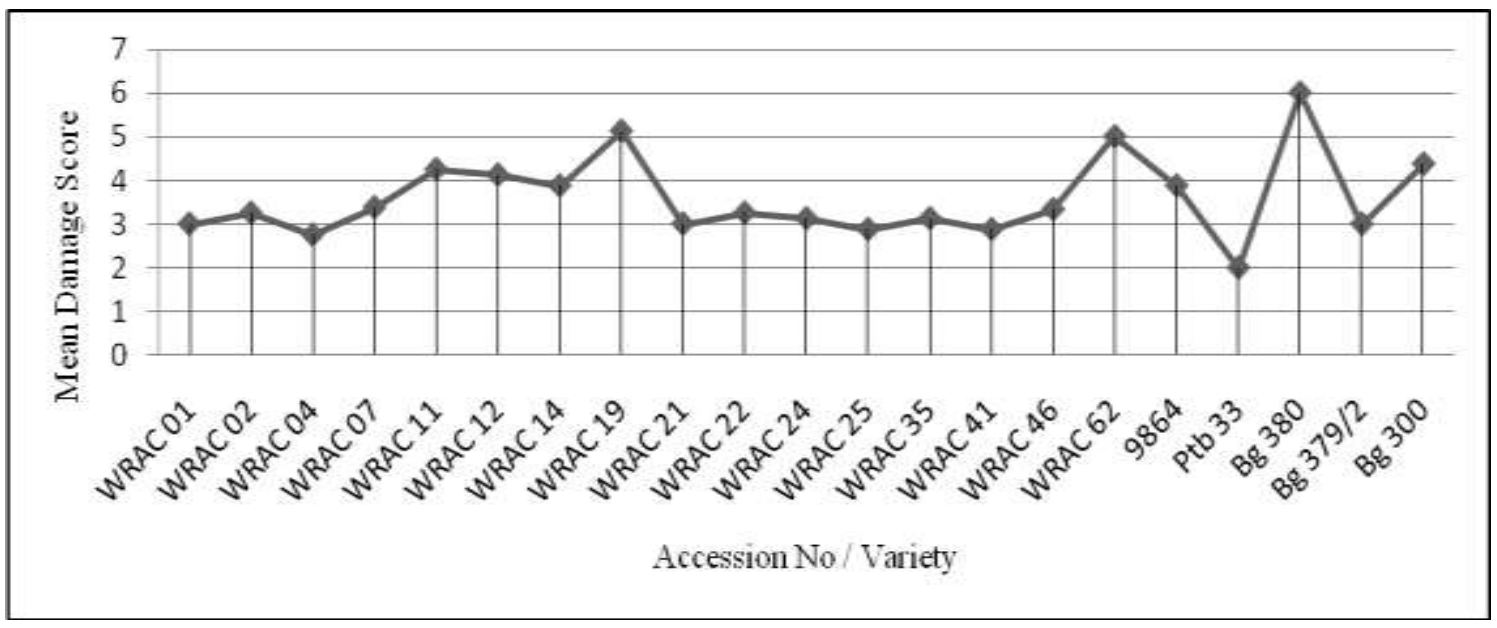

Figure 1: Variation of mean damage score in tested accessions and varieties

According to the scale of the standard evaluation system of BPH resistance, Ptb 33, WRAC 04, WRAC 25 and WRAC 41 recoded as resistant to BPH as all the other O. nivara accessions were categorized under the resistant to moderately resistant, moderately resistant and moderately resistant to moderately susceptible groups (Table 3).

Table 3: Type of resistance recorded in tested $O$. nivara accessions and check varieties

\begin{tabular}{ll}
\hline Type of resistance & Accession No/Variety \\
\hline Resistant(R ) & WRAC 04, WRAC 25, WRAC 41, Ptb 33 \\
$\begin{array}{l}\text { Resistant/Moderately } \\
\text { Resistant(R/MR) }\end{array}$ & WRAC 01, WRAC 02, WRAC 07, WRAC 14, WRAC 21, \\
& WRAC 22, WRAC 24, WRAC 35, WRAC 46, 9864, Bg 379/2 \\
$\begin{array}{l}\text { Moderately Resistant(MR) } \\
\begin{array}{l}\text { Moderately Resistant/Moderately } \\
\text { Susceptible(MR/MS) }\end{array} \\
\text { Susceptible(S) }\end{array}$ WRAC 11, WRAC 12, Bg 300 \\
\hline
\end{tabular}

According to the results no checked $O$. nivara accession was recorded as susceptible to the $\mathrm{BPH}$ indicating potential of using $O$. nivara as donors of $\mathrm{BPH}$ resistance for the future rice variety improvement program in Sri Lanka. 


\section{CONCLUSION}

Results of the BPH bioassay revealed that most of the tested $O$. nivara accessions were resistant to the Sri Lankan BPH. Resistance observed in these accessions may be due to already identified BPH resistant genes or due to new genes. So further experiments should be carried out with markers for already identified BPH resistant genes to detect whether that the resistance observed in $O$. nivara accessions is due to existing resistant genes or new genes to avoid genetic uniformity of $\mathrm{BPH}$ resistance in cultivated rice in future.

\section{REFERENCES}

Heinrichs, E. A., Medrano, F. G., Rapusas, H. R., 1985. Genetic evaluation for insect resistance in rice, International Rice Research Institute, Los Banos, Laguna, Philippines, 45-173.

Hemachandra, P.V., Nawarathne, N.M.N., Dissanayake, D.W.A.J., Geethica, W.U.S., 2010. Morphological characterization of wild rice accessions collected from Sri Lanka. Conservation and utilization of crop wild relatives of Sri Lanka. Book of abstracts, Department of Agriculture and Ministry of Environment and Natural resources, Sri Lanka, 20-21.

Kudagamage, C., Nugaliyadde, L., 1995. Present status and future direction of insect pest management in rice. In (Eds. S. L. Amarasiri, K. Nagaraj, B. M. K. Perera), Rice congress, Sri Lanka, 39-50.

Nugaliyadda, L., Amarasinghe, A. A., Hidaka, T., 2001. The rice brown plant hopper outbreak in 1997/1998 Maha season. Strategies to improve rice pest management in Sri Lanka.3: In: Wijesekara G.A.W., Kotagama H.B, wijesundara D.S.A. (eds). Annals of the Sri Lanka Department of Agriculture, 185-194.

Pathak, M. D., Kush, G. S., 1979. Studies of varietal resistance in rice to brown planthopper at the International Rice Research Institute. In: Brown Planthopper: Threat to rice production in Asia, IRRI, Loss Banos, Phillippines, 285-301.

Wu J. T., Heinrichs E. A., Medrana F. G., 1986. Resistance of wild rice Oryza spp to the brown planthopper, Nilaparvata lugens (Homoptera: Delphacidae).Environmental Entomology 15: 648-653. 